\title{
Recall of categorized and unrelated lists with complete versus discrete presentation and fast versus moderate presentation rates
}

\author{
JAMES W. HALL, BEVERLY E. COX, and MARGARET B. TINZMANN \\ Northwestern University, Evanston, Illinois
}

\begin{abstract}
In Experiment 1, free recall was higher after complete presentations of 20-word lists for $48 \mathrm{sec}$ than after one list presentation at a 2.4-sec rate or four presentations at a 0.6 -sec rate. The latter two conditions yielded nearly equal free recall; there was no interaction between list type and presentation condition. Category clustering was greater with complete than with discrete presentation, but within conditions, there was no relationship between clustering and free recall. In Experiment 2, instructions to use our organizational study strategy with complete lists did not improve recall. These results do not support an organizational-strategy explanation of the superiority of complete presentation. The presentation-rate results are consistent with prior data that had indicated a similarity of effectiveness for free recall of rates from about 0.5 to $3 \mathrm{sec}$; implications of that conclusion are discussed.
\end{abstract}

A central concern of the two experiments reported here is an empirical phenomenon recently observed by Hall, Smith, Wegener, and Underwood (1981, Experiments 1 and 2). That phenomenon was the superiority of free recall when a list of unrelated nouns was presented in complete form (i.e., the entire list was displayed for study) over that with the more customary discrete (successive) presentation of items. A possible explanation of that superiority is that complete presentation is especially conducive to strategic organizational activities, which in turn leads to better recall. The present experiments were designed to examine that possibility. In Experiment 1, complete and discrete presentation were compared for lists containing four members of each of five categories as well as for lists of unrelated nouns. The reasoning was that if the superiority of complete presentation is a result of increased organization, then that superiority ought to be greater with category lists, category clustering should be greater with complete than with discrete presentation, and free recall should be positively correlated with clustering within the different presentation conditions.

Two rates of discrete presentation were employed in Experiment 1, with total study time (TST) held constant by covarying frequency of list presentation. In the $1 \times 2.4$ condition, each list was presented once at a 2.4-sec rate, whereas in the $4 \times 0.6$ condition, each list was presented four consecutive times at a $0.6-\mathrm{sec}$ rate before testing. One reason for this manipulation was that it seemed possible that the relative effectiveness of complete and discrete presentation might vary with the

Experiment 1 was reported at the annual meeting of the Psychonomic Society, Minneapolis, November 1982. Requests for reprints should be addressed to James W. Hall, Department of Psychology, Northwestern University, Evanston, IL 60201. particular presentation rates involved. Presentationrate comparisons are interesting for other reasons also, as will be discussed following a presentation of our results.

\section{EXPERIMENT 1}

\section{Method}

Subjects and Design. The subjects were 36 Northwestern University students, half of whom studied categorizable and half unrelated lists. Each subject studied and recalled nine lists, three consecutive lists within each of three presentation conditions: complete, $1 \times 2.4$, and $4 \times 0.6$. Order of the presentation conditions was completely counterbalanced, so that within each list-type condition, 3 of the 18 subjects served in each of the six possible order conditions.

Materials and Procedure. Each list consisted of 20 randomly ordered moderate- to high-frequency nouns. Each related list comprised four instances of each of 5 categories, taken from the Battig and Montague (1969) norms. The category members ranged from the 4 th to the 12 th most frequently given response in a given category; 45 different categories were used to form the nine related lists. The unrelated lists consisted of nouns similar in frequency to the related words, but selected to minimize obvious semantic relationships among the words. The subjects were fully instructed as to the procedures and requirements of the task, and a brief practice list was given before the three critical lists in each presentation condition. Presentation was visual, using Apple II computers. For the complete condition, each list was displayed on a CRT in two columns of 10 words each for a period of $48 \mathrm{sec}$. For the $1 \times 2.4$ condition, each list was presented once at the rate of $2.4 \mathrm{sec}$ per item, with negligible time between items. For the $4 \times 0.6$ condition, each list was presented four times consecutively and in the same order, at a $0.6-\mathrm{sec}$ rate. Immediately following presentation, the subjects were given a sheet for written recall during a 2-min test period.

\section{Results}

The results of Experiment 1 are summarized in Table 1. These means are based on sums across the three lists within each presentation-method condition. The 
Table 1

Recall in Experiment 1

\begin{tabular}{lccccc}
\hline & \multicolumn{4}{c}{ List Type } \\
\cline { 2 - 3 } \cline { 5 - 6 } $\begin{array}{c}\text { Presentation } \\
\text { Condition }\end{array}$ & Mean & SD & & Mean & SD \\
\cline { 2 - 3 } & Unelated & & & \multicolumn{2}{c}{ Related } \\
\hline Complete & 31.39 & 7.38 & & 46.39 & 6.04 \\
$1 \times 2.4$ & 28.78 & 5.40 & & 41.67 & 6.33 \\
$4 \times 0.6$ & 28.28 & 6.06 & & 40.28 & 6.35 \\
\hline
\end{tabular}

Note-Maximum possible recall $=60$.

clustering scores employed here are the ARC scores (Roenker, Thompson, \& Brown, 1971), for which a score of 0 represents chance clustering and a score of 1 denotes maximum clustering.

The related lists were recalled better than the unrelated lists, as would be expected, and within each list type the complete condition yielded higher recall than the discrete conditions. The difference between the $1 \times 2.4$ condition and the $4 \times 0.6$ condition was negligible. These conclusions were supported by an ANOVA in which list type $[\mathrm{F}(1,24)=54.93, \mathrm{MSe}=86.90]$ and presentation method $[\mathrm{F}(2,48)=13.84, \mathrm{MSe}=14.90]$ were significant. Neither the main effect of order of presentation conditions nor any of the interactions approached significance, with a criterion of $p<.05$ for this and our other analyses.

The clustering data for the related lists paralleled the recall results: Clustering was substantially greater in the complete condition (mean $=.90$ ) with, again, a small difference between the two discrete conditions (.75 and .69 for the $1 \times 2.4$ and $4 \times 0.6$ conditions, respectively). The only significant effect statistically was that of presentation method $[\mathrm{F}(2,24)=8.10, \mathrm{MSe}=.025]$. If the superiority of complete presentation resulted from greater use of an organizational strategy, then one might expect to find a substantial relationship between clustering and recall scores within presentation conditions, especially within the complete condition. In fact, however, for each condition the $r$ was very low $(.10-.12)$ and not significant statistically. However, in the case of the complete condition, the range of clustering scores was quite small (.69-1), making it difficult to interpret the absence of a significant correlation for that condition. Thus, the results confirm the notion that complete presentation is more conducive to organization than is discrete presentation, but fail to provide convincing support for the idea that it is such organization that accounts for greater free recall with complete presentation.

The equivalent efficiency for free recall of the 0.6and 2.4-sec rates is consistent with earlier results by Roberts (1972), as we see it. In Robert's experiment, free recall was similar for a 40 -word list presented at a $0.5 \mathrm{sec}$ rate and a 20 -word list presented at a $1 \mathrm{-sec}$ rate. A 40-word list presented at a 1 -sec rate and a 20-word list presented at a 2 -sec rate also yielded similar free recall. This suggests equivalent efficiency for presentation rates from 0.5 through $2 \mathrm{sec}$ per item. By contrast, Roberts found lower recall for a 10 -word list at a 2 -sec rate than for a 20 -word list at a $1-\mathrm{sec}$ rate. However, it seems almost certain that a severe ceiling effect with the 10 -word list produced the latter difference.

\section{EXPERIMENT 2}

Although Experiment 1 offered little support for an organizational-strategy explanation of the superiority of complete presentation, that possibility could not be regarded as eliminated. Thus, Experiment 2 pursued that notion further by manipulating study instructions with complete list presentation.

\section{Method}

Subjects and Design. The subjects, 48 Northwestern University students, were assigned randomly to three groups of 16 subjects each. Every subject was given one study-recall trial on each of four 20-word lists. Before presentation of the first list, the subjects receiving standard instructions were informed of the nature of the task and urged to do their best. The organization subjects were told: "Be attentive to relationships among words; see if you can tie various words together. In other words, use an organizational strategy to help you remember the words." The recycle group was told: "Go through the list rehearsing each word briefly and recycling through the words until your study time is up." The third group was given standard (neutral) study instructions.

Materials and Procedure. Four lists of 20 unrelated twosyllable nouns of moderate frequency were given in the same random order to all subjects, with the first list serving as a practice list. The task was explained and appropriate study instructions given in writing so that the subjects could be run in groups that were mixed with respect to study instructions. The study lists were typewritten on individual sheets. The subjects had $80 \mathrm{sec}$ in which to study each list, followed immediately by a 2 -min recall period.

\section{Results}

The free-recall means summed across the final three lists were $40.75(\mathrm{SD}=8.98), 38.5(\mathrm{SD}=9.56)$, and $40.92(\mathrm{SD}=11.11)$ for the organize, recycle, and standard conditions, respectively. The differences among these means did not approach statistical significance, again failing to support an organization-strategy account of the superiority of complete presentation. The absence of free-recall differences apparently was not due to the failure of the instructions to induce different study strategies. This was checked by examining the extent to which the order of recall mirrored order in the study list. If the instructions affected subject study strategies in the desired way, then (we assumed) the correspondence between study order and recall order should be greatest for the recycle condition and least for the organize conditions. This is precisely what was found for each list. The index of this correspondence was the number of items that were adjacent in both study and recall divided by the total number of items recalled. The respective means for the recycle, organize, and standard conditions were $.47, .25$, and .34 , and the differences were 
statistically significant $[\mathrm{F}(1,45)=3.80, \mathrm{MSe}=.32]$. It appears, then, that the study instructions affected study behavior without any detectable corresponding effect on recall.

\section{DISCUSSION}

In addition to the present study, there have been five experiments from our laboratory in which complete and discrete presentation were compared. Three of these were free-recall experiments, one involving discrete presentation rates of 2, 4, and $6 \mathrm{sec}$ per item (Hall, Smith, Wegener, \& Underwood, 1981, Experiment 1), one comparing rates of 1 and $4 \mathrm{sec}$ (Hall, Wegener, \& Underwood, Experiment 2), and the third using a rate of 5 sec per item (Hall, Grossman, \& Elwood, 1976, Experiment 1). The others were paired-associates learning (PAL) experiments; one compared rates of 2 and $6 \mathrm{sec}$ (Hall, Smith, Wegener, \& Underwood, 1981, Experiment 3), and the other used a rate of $10 \mathrm{sec}$ per item (Hall, Wilson, \& Patterson, 1981, Experiment 4). The same pattern emerges for free recall and PAL when these experiments are examined together: The superiority of complete to discrete presentation is considerably greater with the slowest of the above rates than with the faster ones. That difference (interaction) apparently is due to the slower rates' being less than optimal for discrete presentation. Nevertheless, even at what appear to be optimal or near-optimal presentation rates, there is a small but quite consistent superiority of complete presentation that requires explanation.

In light of the present data, one plausible account of the superiority of complete presentation for free recall now seems unlikely. According to that account, organization of items is facilitated by complete presentation, thus accounting for the better recall. Indeed, it appears that organization is facilitated by complete presentation, given that category clustering was substantially greater for that condition in Experiment 1 . However, it seems doubtful that this fully accounts for the typical superiority of complete presentation in our experiments. By our reasoning, if greater organization were the explanation, then the superiority of complete presentation would be substantially greater with category than with unrelated lists, clustering within conditions would be related to recall, and instructions to organize would enhance recall. None of these results were obtained.

With respect to presentation-rate effects, the present results converge with those of Murdock (1960, Experiment XI), Postman and Warren (1972), and Roberts (1972) to indicate that rates from about 0.5 to about $3 \mathrm{sec}$ are similar in their effectiveness for free recall provided, of course, that TST is held constant.
The results of experiments by Hall, Smith, Wegener, and Underwood (1981, Experiment 2) and Roberts (1972) also agree in showing lower effectiveness of a $4-\mathrm{sec}$ than of a 1-sec presentation rate. These conclusions are made more convincing by the fact that close agreement was found despite the use of different procedures by which TST was equated. This was done by covarying list length in the Murdock, the Postman and Warren, and the Roberts experiments, and by covarying frequency of list presentation in the remaining experiments. The picture suggested by these results is that the contribution of processing, per unit of time, to subsequent recall must be maximal almost immediately upon the initiation of perceptual operations and well prior to deliberate initiation of rehearsal activities. Furthermore, a decline from that maximal rate of memory input evidently begins well before the end of a 4-sec study interval.

\section{REFERENCES}

Battig, W. F., \& Montague, W. E. (1969). Category norms for verbal items in 56 categories: A replication and extension of the Connecticut norms. Journal of Experimental Psychology Monographs, 80(3, Pt. 2).

Hall, J. W., Grossman, L. R., \& Elwood, K. D. (1976). Differences in encoding for free recall vs. recognition. Memory \& Cognition, 4, 507-513.

Hall, J. W., Smith, T. A., Wegener, S. L., \& Underwood, B. J. (1981). Rate and frequency as determinants of learning with complete and discrete list presentation. Memory \& Cognition, 9, 360-367.

Hall, J. W., Wilson, K. P., \& Patterson, R. J. (1981). Mnemotechnics: Some limitations of the mnemonic keyword method for the study of foreign language vocabulary. Journal of Educational Psychology, 73, 345-357.

MURDOCK, B. B., JR. (1960). The immediate retention of unrelated words. Journal of Experimental Psychology, 60, 222-234.

Postman, L., \& Warren, L. (1972). Test of the total-time hypothesis in free-recall learning. Journal of Experimental Psychology, 96, 176-183.

RoBerts, W. A. (1972). Free recall of word lists varying in length and rate of presentation: A test of the total-time hypothesis. Journal of Experimental Psychology, 92, 365-372.

Roenker, D. L., Thompson, C. P., \& Brown, S. C. (1971). Comparison of measures for the estimation of clustering in free recall. Psychological Bulletin, 76, 45-48.

(Manuscript received for publication April 5, 1984.) 